See discussions, stats, and author profiles for this publication at: https://www.researchgate.net/publication/7323421

\title{
Mapping an appropriate health promotion approach for creches in an informal settlement
}

Article in International Journal of Dental Hygiene · March 2005

DOI: 10.1111/j.1601-5037.2004.00116.x · Source: PubMed

CITATION

1

2 authors:

Pradeep Brijlal

University of the Western Cape

19 PUBLICATIONS 302 CITATIONS

SEE PROFILE

Some of the authors of this publication are also working on these related projects:

Project student (oral hygiene) stress in the dental environment View project

Project Same aurthor but differnt papers View project
READS

27
Natalie Ann Gordon

University of the Western Cape

20 PUBLICATIONS 98 CITATIONS

SEE PROFILE 


\section{P Brijlal \\ $N$ Gordon}

\section{Mapping an appropriate health promotion approach for crèches in an informal settlement}

\section{Authors' affiliation:}

$P$ Brijlal, $N$ Gordon, Department of Oral Hygiene, Faculty of Dentistry, University of the Western Cape, Bellville, Western Cape, South Africa

\section{Correspondence to:}

Priscilla Brijlal

Department of Oral Hygiene

Faculty of Dentistry

University of the Western Cape

Private Bag X17

Bellville, 7560

Western Cape

South Africa

Tel.: +270219373126

Fax: +270219312287

E-mail: prbrijlal@uwc.ac.za

\section{Dates:}

Accepted 10 November 2004

\section{To cite this article}

Int J Dent Hygiene 3, 2005; 31-36

Brijlal P, Gordon N:

Mapping an appropriate health promotion approach

for crèches in an informal settlement

Copyright $\odot$ Blackwell Munksgaard 2005

\begin{abstract}
Background: People living in informal settlements in South Africa experience the double burden of poverty and ill health. Wallacedene, an informal settlement was highlighted in the media as being a socially and otherwise deprived community, with many accompanying health problems. Aim: It was against this background that this study was conducted to gain a better understanding of the health and oral health status of children attending crèches in Wallacedene. It was designed to inform the mapping of an appropriate approach to develop a health promotion programme for crèches. Method: Baseline data were collected through oral and general health examinations, site observations, a structured questionnaire and interviews with key people working with the children at two crèches. Results: The results indicate poor oral and general health. Gingival inflammation (82.8\%), caries (81.5\%), and moderate to abundant plaque deposits (95.7\%), fungal infections (33.9\%), runny nose $(51.4 \%)$, lymphadenopathy $(45.7 \%)$ and itchy skin $(5.7 \%)$ were found. Caregivers were not well informed about oral health. However, they were enthusiastic to engage in new interventions. The community was impoverished; public health interventions were limited with minimal resources such as health centres and voluntary service providers. The limited resources were not coordinated and did not adequately address the health and educational needs of the children. Conclusion: A multi-sectoral approach focusing on community development is an appropriate approach to address the needs of crèche children in this community.
\end{abstract}

Key words: oral health promotion; programme planning; informal settlements; community development; multi-sectoral; settings approach 


\section{Introduction}

Globally, ill health in developing countries are attributed to socio-economic factors, poverty, lack of resources and support structures, inequity in health care delivery, inaccessibility to treatment, lack of education, and the impact of urbanization. This is particularly evident in South Africa, a country recovering from decades of an unjust political system (1).

Oral diseases are an important public health problem in South Africa (2). The reasons for their importance are, their high prevalence, public demand for emergency treatment, and their impact on individuals and society in terms of pain, discomfort, social and functional limitation and handicap, and the effect on people's quality of life. Research has long documented that poor oral health status is as a result of self-infliction. 'If only people would practice better oral hygiene, consume less sugar, eat healthy food, buy fluoride toothpaste, and be more interested in their children's teeth, ...' (3). This view creates the impression that one's oral health is primarily dependent on individual lifestyle choices and that these choices are within one's reach. By describing oral health in such individual terms, the social context gets hidden (3).

Dental caries and gingivitis are common oral diseases found in young children. The National Children's Oral Health Survey of South Africa reported a high prevalence of dental caries $(82.3 \%)$ in 5-year olds in the Western Cape Province (2). Studies have shown that health and oral health is evidently worse in low socio-economic areas $(4,5)$ simply because people may not have the resources to deal with oral diseases (6). According to Lalloo (1), health services are also often least accessible and of poorer quality in disadvantaged areas where they are most needed. Bor et al. (7) reported that children living socio-economic disadvantage have a higher rate of service utilization, more chronic health problems and poorer dental health.

When one considers the fact that oral problems are progressive in nature and the impact it has on quality of life especially in poorer communities, it is imperative that interventions are developed that are appropriate to the population concerned. A major lack of success of oral health promotion may be the attempt to build oral health services that are separate and additional to the health care structure (8).

Therefore, in developing health promotion initiatives in informal settlements, it is critical to investigate the socio-economic status of the community, their current health status, type and extent of current interventions and resources that are available for community development.

\section{Background}

Wallacedene is an informal settlement located $25 \mathrm{~km}$ from the city of Cape Town and is home to 8500 families, approximately 20000 people per square $\mathrm{km}$. Almost half of this population are children. Their socio-economic and health conditions were first brought to public attention on a local investigative television programme in South Africa (9).

Of the basic health necessities, people were in great need of appropriate shelter. Homes were made up from tin, wood and plastic sheets. There was lack of adequate safe water, sanitation, waste removal, food, employment, health services and support (Figs. 1 and 2). Wallacedene is situated below the water table; flooding is frequent and the poor drainage

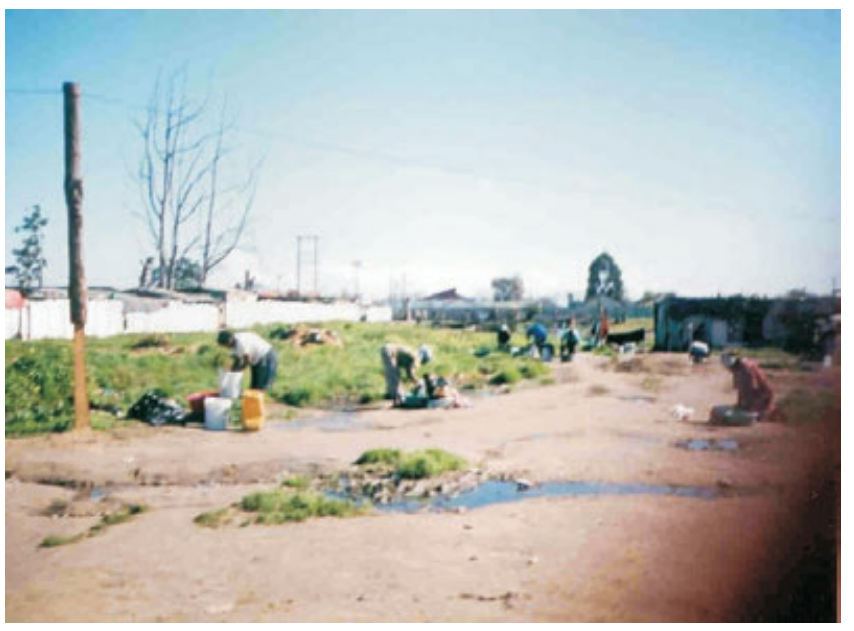

Fig 1. Women folk washing clothing in stagnant water.

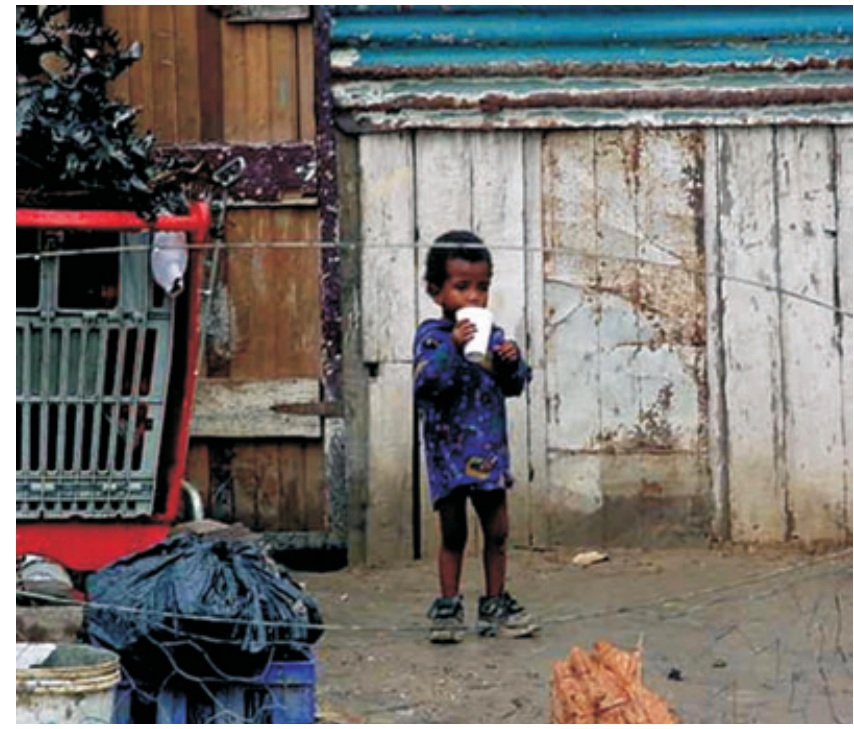

Fig 2. A typical home environment. 
system leads to stagnation of water. This water was at times used to drink, bath, cook or washing clothing. The eight water taps from a single pipe and few toilets placed in 2002, are no longer functional because of high public use. Water is now collected from a distance and the 'pit latrine system' is used. Health problems are many, ranging from fungal infections to AIDS (9). There is a Primary Health Care (PHC) facility about $2 \mathrm{~km}$ away and a child health clinic situated in the settlement. The informal crèches initiated by the community do not meet the government requirements for formal registration and thus are not subsidized by government. Religious voluntary organizations have feeding programmes targeted primarily at children.

This study evolved from questioning our obligation as health workers, especially in areas where health services are lacking, to highlight the plight of disadvantaged communities on a professional and public level. Our aim was to collect baseline data to inform the mapping of an appropriate approach to develop a health promotion programme in crèches in Wallacedene.

\section{Methodology}

The study included a convenience sample comprising of children at two crèches $(n=60$ at each crèche), their caregivers ( $n=5$ at each crèche), a voluntary social worker and an oral hygienist (Fig. 3). Only children present on the day of examination were included. An oral examination was conducted to record the decayed, missing and filled teeth; the presence or absence of gingival inflammation and plaque deposits and their extent; and any soft tissue lesions. A mouth mirror, tongue depressor, disclosing tablets and natural light was used. A gen-

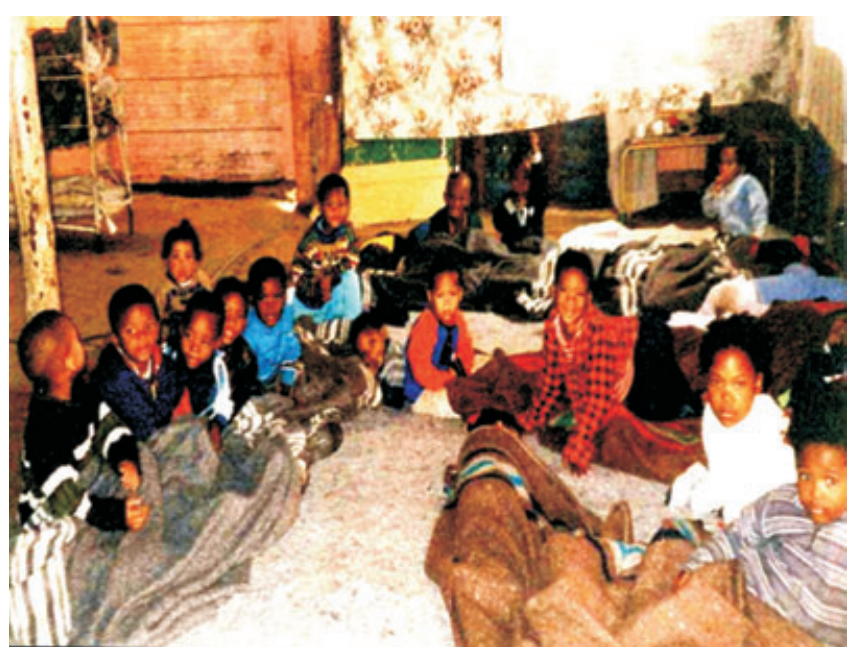

Fig 3. Children in the crèche. eral examination for the presence of visible sores and infections on the body was included.

A structured questionnaire for crèche caregivers assessed their: knowledge, attitude, behaviour and practices about oral health, current oral health programmes and their interest in an expanded oral health programme. Interviews and general observations gave further insight into the above topics.

\section{Results}

The response rate for the children at the two crèches was $60 \%$ $(n=38)$ and $50 \%(n=32)$ respectively. All the caregivers $(n=10)$ responded. Children's ages ranged from 2 to 6 years (mean: 3.9). The oral examination revealed a range of decayed teeth from 1 to 17 (mean $=4)$, gingival inflammation $(82.8 \%)$, caries $(81.5 \%)$, and moderate to abundant plaque deposits $(95.7 \%)$ and minimal ulcers on the lips. The general examination found fungal infections (33.9\%), runny nose $(51.4 \%)$, lymphadenopathy $(45.7 \%)$ and itchy skin (5.7\%).

The questionnaire revealed the caregivers' knowledge of oral diseases. Gingival inflammation was associated with 'very hot or cold things'; dental caries was associated with not brushing or too many sweet things; healthy teeth were a result of a healthy diet. Children received fruit, sandwiches with jam, cakes, biscuits, milk and fruit juice daily. Caregivers educated the children on health and oral health using drawings, storytelling and role-playing. They did not examine the children's mouths. They were positive about having oral health education as part of their programme and very interested in an expanded programme, if offered. Caregivers reported high absenteeism and that the classroom facilities were inadequate. The ventilation was considered to be poor and toilet facilities were common to the rest of the community.

The only interaction the crèches had with other service providers was the voluntary social worker. The social worker serviced the area on a voluntary basis and frequently visited the crèche children to perform first aid. The oral hygienist reported that she had contact with the community only when the residents visited the dental clinic at the PHC facility.

The caregivers, social worker and some community members reported that residents did not generally feel comfortable visiting the PHC facility. Although the community felt the service was accessible, they perceived it to be unacceptable and unavailable because of the negative attitude of staff towards them. Observations in the environment revealed that nothing has changed since the television broadcast. Squalor, overcrowd- 
ing, alcohol abuse, ill health, and lack of food, housing and services were evident.

\section{Discussion}

The status of this community is summarized by Feuerstein (10): 'the most vulnerable in a population are those for whom multiple deprivations converge, such as lack of food, shelter, safe drinking water, health care, education and employment. They suffer from lack of assets, items and opportunity for which land and money can provide. This is a condition of absolute poverty and vulnerability. For such people, the challenges of daily survival are endless and achieving a reasonable standard of health is difficult'. The lack of basic hygiene facilities and health care services largely determines the general and oral health of these children.

The high plaque scores appears to contradict the report of daily brushing at one crèche, suggesting that this school activity is not performed daily. It further suggests that, daily oral hygiene, is not practised by the majority of the children. The fact that all children have at least one carious tooth with some having almost all their primary teeth carious at this early age is a matter of concern. It clearly shows that the oral health of this small sample reflects the dental status of the child population of the province. Pain and function were not assessed in this study, yet the high prevalence of rampant caries suggests that many children may have compromised dental function and acute or chronic dental pain. Absenteeism from crèches may be a further indicator of how their compromised oral health status impacts on their general well being. This may result in limited opportunity for learning and the children's development may be further compromised.

Crèche personnel report to providing education on health, life skills and daily brushing. The level of care they provide is dependent on their knowledge and skills, and the resources they are able to access. In the oral health component, caregivers educate children about dental caries and gingivitis, and the prevention thereof. However, their oral health literacy is poor with a lack of clarity about the causes and prevention of caries and gingivitis which are two major problems found amongst the crèche children. Considering their living conditions, social problems and general health problems, these children may experience oral health problems associated with malnutrition, trauma and systemic conditions, conditions of which caregivers may not appear to be aware. Thus, caregivers may not have the knowledge to educate the children and may not understand the implications of oral problems that children report to them. They may further provide inaccurate information resulting in children adopting the health beliefs of caregivers.

The crèche programme, and general enthusiasm for outside involvement including expanded oral health interventions shows a commitment to improve the care provided at these facilities. It is reflected in the type and extent of their daily activities to obtain maximum benefit to the children. The educational strategies such as storytelling and role-play, is very appropriate for this age group and generally used at crèche level. This again shows how activities mirror those in formal crèches and the broader society. The overcrowding at both crèches does not create an environment conducive to learning, and may promote antisocial behaviour further exacerbating their already challenging environment. Absenteeism may also be the result of the inadequate infrastructure making the crèches an environment that is no different from home. The limited public sector input makes it more difficult for these crèches to function when compared with registered formal crèches, further disadvantaging them.

The lack of coordination in community and other structures means that the limited resources are not being effectively utilized. Religious organizations and voluntary workers have targeted this area to help alleviate the destitution that they observed in community. The vision of the donors are centred on providing sustenance from a compassionate view, which in essence does not make these services sustainable but rather creates a sense of dependency. Hence, the responsibility of government in first, acknowledging informal settlements and secondly, in providing appropriate health and education, cannot be over emphasized.

South Africa has adopted the PHC approach (11). This in essence means that basic health services that are scientifically sound, culturally appropriate, available, affordable and accessible should be made available to all citizens. Within the healthcare system, children under 6 years and pregnant women have access to free health and oral health services. Despite the fact that legislation intended to reduce inequities in healthcare, the caries prevalence in the children is high and no dental services are offered in the settlement. The limited basic services and the perceived inaccessibility of these services may compound many problems faced by this community.

The existence of an informal settlement with all the accompanying health and social problems within the proximity of a major city as Cape Town raises the question of the responsibility of civil society in reducing inequity. The use of the media to highlight their plight and advocate for change has yielded little response from government; and a general sense of indif- 
ference from the broader public, further contributing to their sense of alienation. Changing the environment is a factor largely outside the control of the health professional. Therefore an innovative health promotion intervention is required to support the crèche community in enhancing the well being of the children. Interventions focusing solely on behaviour change would therefore be inappropriate and of limited value.

Community development, participation and the integrated services approach have become the essence of health promotion (3). It is well documented that when people are part of the planning and implementation of programmes, there is greater chance of positive change (12). The community participatory approach was shown to be useful and feasible to address oral health concerns in communities not reached by traditional dental health and health promotion initiatives (13). The existence of the crèches, their enthusiasm to engage with new interventions and the resources although limited makes this approach very possible in Wallacedene.

Based on the findings, the 'settings approach' in health promotion is proposed. This approach is centred on environments and social groupings of people rather than disease and symptoms. It encourages community, multidisciplinary and multiagency participation and an emphasis on PHC (11). The goal would thus be to create healthier crèches. The first step would be to form a community forum of all stakeholders including school community members, caregivers, local authorities, service providers in the area and volunteers, to consolidate resources and develop a vision for healthier crèches. The forum would then need to brainstorm the issues that they are faced with and use their combined skills to set appropriate and reasonable targets for change. Such collaboration will require individuals and groups to form a common agenda while leaving some leeway to pursue their own visions. This will require a change of attitude and behaviour of all stakeholders as this study shows that agencies, professionals and other stakeholders operated mainly in isolation of one another.

The five action areas identified in the Ottawa Charter (14) may guide the process. The first is to strengthen community action. The school community in conjunction with the community forum can identify its needs, priorities and best ways to meet these needs within the constraints of their resources. The second is to create a healthy physical and social environment. This may include improving the physical facilities such as the building, sanitation and play area; and working towards a more supportive relationship between the school community and other role-players. The third is to develop the personal skills of caregivers, parents, children and service providers. These may include the skills required by all involved to real- ize the vision of a healthier crèche such as life-skills, basic first aid, doing a basic oral examination, health and oral health literacy; building skills, gardening and teaching oral health care. Community members/caregivers can be educated about prevailing health problems specific to the community and trained to initiate health programmes. The fourth is to reorientate health services to be more sensitive to community needs and to provide culturally accepted services. Immunization, family planning, dental care and other services can be provided at the settlement and crèches as a mobile clinic. PHC staff can visit the crèches for dental and health screening and educate caregivers and parents about prevailing health problems and prevention. The fifth is to develop healthy policies to entrench the action areas described annual dental and health checkups, daily hygiene practices as part of the crèche curriculum, a healthier and affordable food selection at crèches, regular meetings of the community forum amongst others. Effective health promotion tools might involve advocacy to alert government to appropriate issues and for different agencies to work towards common goal; mediation between different groups as stakeholders may not agree on policies or interventions; and enablement by improving structures and continuously build capacity of the community and stakeholders.

The skills and resources developed may be transferred to other groupings in the community and so create a ripple effect on the rest of the settlement. This approach is more likely to empower those in authority, and to include community development and inter-sectoral collaboration; thus it is be more likely to be sustainable.

\section{Conclusion}

For most people in the world today, every step of life from infancy to old age is taken under the twin shadows of poverty and inequity, and under the double burden of suffering and disease. For many, the prospects of longer life may seem more like a punishment than a gift (15).

Although Wallacedene is a reflection of a deprived community, community development is evident by virtue of the crèches being created out of community needs (Fig. 4). This in a sense mirrors the activities that are practiced in the broader society. It clearly shows the community's capacity to define its needs and take action.

The results of this study show that there is a need of appropriate intervention. The thinking around interventions should thus be to empower and enhance what is being done. Whilst public health interventions are limited, this community has access to resources such as health centres, voluntary services 


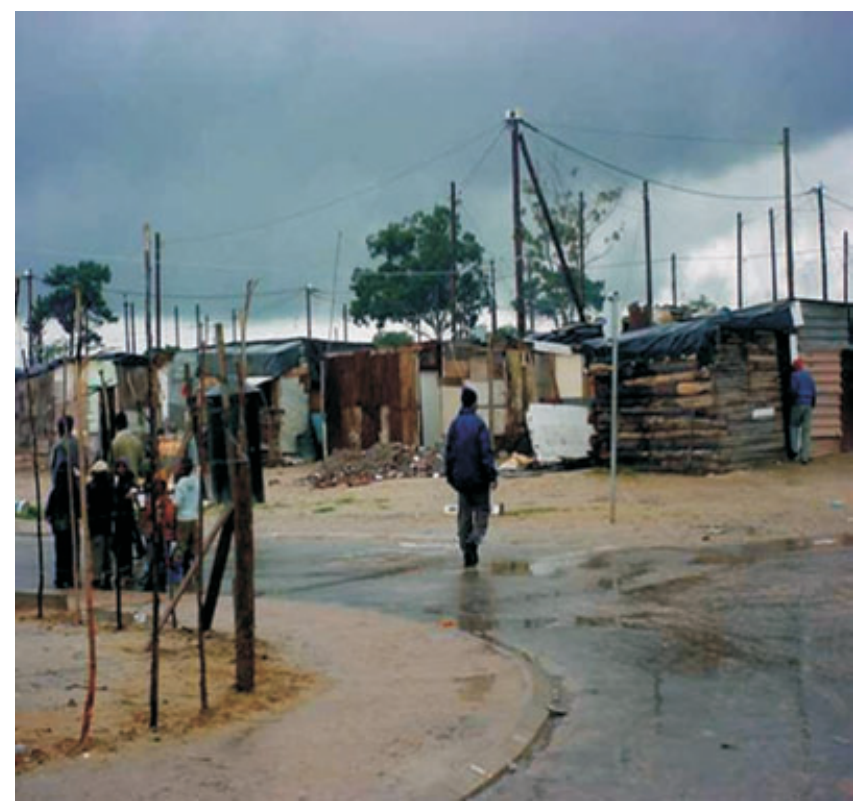

Fig 4. Wallacedene: Typical housing and environment.

and caregivers who are motivated to make improvements in the crèches. However, this is not adequate and highlights the responsibility of government in providing appropriate health care and education.

Governments have a responsibility for the health of their people that can be fulfilled only by the provision of adequate health and social measures as part of development in the spirit of social justice $(16,17)$. As health care workers and educators, our responsibility is to ensure that health promotion is adequately and appropriately planned and executed. In addition they should be, effective, economically and practically feasible. If this is not done, we run the risk of programmes paying lip service to public health problems and not effecting change (18). Therefore a multi-sectoral approach focusing on community development is an appropriate approach to address the needs of crèche children in this community.

\section{Acknowledgements}

We wish to thank the crèche community, the social worker and oral hygiene students (Ms Brackman and Ms Carelson) for their contribution.

\section{References}

1 Lalloo R. Equity in health revisited. J Compr Health 1995; 6: 199 201.
2 Van Wyk PJ. Report: National Children's Oral Health Survey South Africa. Department of Health: South Africa. 2003: 2-17.

3 Dickson M. Focus on health promotion. In: Mautsch W, Sheiham A, ed. Promoting Oral Health in Deprived Communities. German Foundation for International Development: Berlin, Germany. 1995: 175-186.

4 Hirschowitz R, Orkin M. Research findings: children aged five years and younger. In: Sinclair M, Tyson J, eds. Learning Problems and Remedial Education. The National Household Survey of Health Inequalities in South Africa: Washington DC. 1995: 25-48.

5 Oral Health Alliance. The Berlin declaration on oral health and oral health services in deprived communities. In: Mautsch W, Sheiham A, eds. Promoting Oral Health in Deprived Communities. German Foundation for International Development: Berlin, Germany. 1995: 61-82.

6 Mautsch W. Introduction. In: Mautsch W, Sheiham A, eds. Promoting Oral Health in Deprived Communities. German Foundation for International Development: Berlin, Germany. 1995: 13-19.

7 Bor W, Najman JM, Anderson M, Morrison J, Williams G. Socioeconomic disadvantage and child morbidity: an Australian longitudinal study. Soc Sci Med 1993; 36: 1053-1061.

8 World Health Organization. Research and action for the promotion of oral health within primary health care. In: Mautsch W, Sheiham A, eds. Promoting Oral Health in Deprived Communities. German Foundation for International Development: Berlin, Germany. 1995: 279-282.

9 Third Degree Special Assignment. Wallacedene, The Forgotten Place. South African Broadcasting Corporation 3: Johannesburg, South Afirca. 2000.

10 Feuerstein M. Poverty and Health: Reaping a Richer Harvest. Macmillan: Hong Kong, China. 1997. 7.

11 World Health Organization (WHO). World Health Organization targets for health for all. Copenhagen: WHO. In: Coulson N, Goldstein S, Ntuli A, ed. Promoting Health in South Africa, An Action Manual. Heinemann Higher and Further Education: Sandton. 1998: 7-8.

12 Hecker EJ. Implementation and evaluation of a communitywide health fair. Public Health Nurs 2000; 17: 247-256.

13 Watson MR, Horowitz AM, Garcia I, Canto MT. A community participatory oral health promotion program in an inner-city Latino community. J Public Health Dent 2001; 61: 34-41.

14 Dickson M. Focus on health promotion. The Ottawa Charter for Health Promotion. In: Mautsch W, Sheiham A, eds. Promoting Oral Health in Deprived Communities. German Foundation for International Development: Berlin, Germany. 1995: 175-186.

15 Mail and Guardian newspaper. In: Gilbert L, Selikow T, Walker L, eds. Society Health and Disease. Ravan Press: Braamfontein, South Africa. 1995: 99.

16 Alma Ata Declaration. Guiding principles for improving oral health. In: Mautsch W, Sheiham A, ed. Promoting Oral Health in Deprived Communities. German Foundation for International Development: Berlin, Germany. 1995: 68-73.

17 World Health Organization (WHO). Primary Health Care, Alma Ata 1978. Health for All Series No. 1, WHO: Geneva, Switzerland. 1978.

18 Reddy P, Kok G, Van Der Borne B, Yach D. Unraveling health promotion: in pursuit of more successful interventions. J Compr Health 1995; 6: 110-114. 